\title{
Epistemologia da comunicação intersubjetiva: aproximações sociológicas, filosóficas e interdisciplinares
} Epistemology of intersubjective communication: sociological, philosophical and interdisciplinary approaches

\author{
- Fátima fernández Christlieba \\ Universidad Nacional Autónoma de México, Facultad de Ciencias y Políticas y Sociales. Cidade do \\ México, México \\ MARCO A NTONIO MILLÁN CA M P U Z N O \\ Universidad Autónoma Metropolitana Cuajimalpa, Departamento de Ciencias de la Comunicación. \\ Cidade do México, México \\ MARTA RIZO GARCÍAc \\ Universidad Autónoma de la Ciudad de México, Academia de Comunicación y Cultura. Cidade do \\ México, México
}

\section{RESUMO}

O texto apresenta um mapa de autores e perspectivas para a abordagem da comunicação intersubjetiva. Os antecedentes se encontram nas discussões desenvolvidas no marco do grupo de investigação "Comunicación Intersubjetiva” da Asociación Mexicana de Investigadores de la Comunicación (AMIC). No primeiro momento, são oferecidos alguns elementos para compreender as diferenças básicas entre a comunicação interpessoal e a comunicação intersubjetiva. Posteriormente, são apresentados autores-chave - procedentes da sociologia (Mead, Schütz, Sennett e Collins) e da filosofia (Heidegger, Habermas e Onfray) - para a abordagem da comunicação intersubjetiva; e agregamos mais dois autores, cuja produção é, em nosso entender, eminentemente interdisciplinar (Elias e Maturana). Palavras-chave: Intersubjetividade, comunicação, interdisciplinar

\section{ABSTRACT}

The text presents a map of authors and prospects for an intersubjective communication approach. Antecedents are in discussions developed within the research group "intersubjective communication" of the Mexican Association of Communication Researchers (AMIC). Initially these pages offered some elements to understand the basic differences between interpersonal communication and intersubjective communication. Subsequently, the text presents some authors - from sociology (Mead, Schütz, Sennett and Collins) and philosophy (Heidegger, Habermas and Onfray) - for addressing intersubjective communication; and we added two more authors, whose production is, in our view, eminently interdisciplinary (Elias and Maturana).

Keywords: Intersubjectivity, communication, interdiscipline

${ }^{\text {a }}$ Docente em tempo integral na Facultad de Ciencias y Políticas y Sociales da Universidad Nacional Autónoma de México. Licenciada em Comunicacão, mestre e doutora em Sociologia. Orcid: http://orcid. org/0000-0002-1062-7961. E-mail: fatima@unam.mx

${ }^{\mathrm{b}}$ Professor-investigador do Departamento de Ciencias de la Comunicación da Universidad Autónoma MetropolitanaCuajimalpa. Licenciado em Jornalismo e Comunicação Coletiva e pós-graduado em Filosofia da Ciência. Orcid: http://orcid.org/0000-00028466-1708. E-mail: mmillan@correo.cua.uam.mx

${ }^{\mathrm{c}}$ Profesora-investigadora da Academia de Comunicación y Cultura da Universidad Autónoma de la Ciudad de México. Licenciada em Jornalismo e Ciências da Comunicação e doutora em Comunicação. Orcid: http:// orcid.org/0000-0003-3066-1419. E-mail: marta.rizo@uacm.edu.mx 


\section{APRESENTAÇÃO E ANTECEDENTES}

LINHA DE PESQUISA em comunicação intersubjetiva é uma das mais recentes na Asociación Mexicana de Investigadores de la ComuLnicación (AMIC). Começamos a falar sobre sua formação em 2007, quando seus coordenadores, por diferentes motivos, não sentiam afinidade especial por nenhuma das 16 linhas então existentes. Queríamos nos dedicar a trabalhar no âmbito da comunicação interpessoal, o que acontece entre os seres humanos que a cada dia dispõem de mais instrumentos para trocar mensagens, mas que não parecem comunicar-se melhor. Desejávamos penetrar no território no qual os indivíduos compreendem o outro; onde a negociação racional é factível para chegar a acordos; onde também se depura a emoção e se subverte ou se reforçam os acordos. Buscamos, em suma, trazer aportes para a melhor compreensão do fenômeno da comunicação e, sobretudo, para sua prática cotidiana.

No encontro de 2008, em Monterrei, cada um expôs o que desejava e como entendia o tema. Com isso, elaboramos um primeiro livro, Nosotros y los otros: la comunicación humana como fundamento de la vida social (Fernández; Rizo García, 2009). O apresentamos em Puebla, em 2009, e percebemos então que seria conveniente organizar a discussão, principalmente no nível teórico e conceitual. A pergunta sobre o que entendemos por comunicação intersubjetiva se converteu em nosso eixo de discussão básico. Por isso, em 2010, nos propomos a explicitar o que cada um entendia por comunicação interpessoal e por comunicação intersubjetiva. Para o encontro em Pachuca, em 2011, avançamos e compreendemos que o termo "intersubjetividade" possui uma tensão subjacente e, na história da humanidade, são muitos os pensadores que formularam teorias a respeito; falaremos de alguns deles. Decidimos, portanto, escrever o que então havia se tornado claro para nós, e expusemos os avanços em 2012, em Saltillo. Em 2013, foi publicado nosso segundo livro, La comunicación humana en tiempos de lo digital (Fernández; Millán Campuzano; Rizo García, 2013), e nesse ano o apresentamos informalmente em nosso grupo de trabalho em Toluca; daí saímos convencidos de que há teorias da comunicação intersubjetivas implícitas num grande número de autores clássicos, modernos e contemporâneos.

Hoje, quanto à pergunta sobre as formas pelas quais se tem construído conhecimento sobre a comunicação subjetiva, respondemos que não é no campo acadêmico da comunicação que se encontra a resposta. Aqueles que têm oferecido apoio teórico para a investigação empírica em comunicação intersubjetiva provêm de diversas áreas do conhecimento e, com frequência, são autores que ao colocar suas questões de investigação buscam a resposta como cães de caça atrás da presa, sem preocupar-se com qual disciplina formal atravessam. 
Sabemos que nos inserimos em um campo acadêmico chamado comunicação, porém não desejamos estabelecer fronteiras no território nem declarar a sua autonomia. A comunicação avança mais que a ciência, abarca mais, porque se nutre dela e do conhecimento que está fora dela. Conforme as palavras de quem escreveu um texto que se tornou um clássico da epistemologia, cremos na ciência, nesse "conjunto de saberes compartilhados por determinada comunidade epistêmica: teorias, enunciados postos em relação com um conjunto de objetos, enunciados de observação comprováveis intersubjetivamente" (Villoro, 1982: 228); porém, seguindo o mesmo o autor, também confiamos na sabedoria, porque suas verdades podem comunicar-se ainda que sem palavras. A sabedoria "não expõe razões, nem formula teorias explicativas, narra uma experiência vivida, transmite uma relação direta com as coisas, abre os olhos alheios para que cada um veja por si mesmo" (Ibid.).

Nenhum dos autores que abordamos nesse texto provém de uma única disciplina, nem faz somente ciência; a sabedoria mostra-se nos interstícios de seus postulados teóricos; porém, todos sabem que o que dizem deve ser colocado à prova. No seu trajeto, cruzaram qualquer disciplina que fosse necessário, reinventaram paradigmas dominantes e chegaram, como disse Piaget, a uma etapa superior de integração ou de eliminação das fronteiras entre as disciplinas - alcançaram a transdisciplinaridade.

Em nosso caso, cada um faz seu trabalho em seu próprio objeto de estudo; cada um deixou para trás a tarefa multi ou pluridisciplinar para incursionar na interdisciplinaridade, para chegar onde os termos, conceitos, teorias e práticas começam a mover-se entre áreas que, para efeitos administrativos, estão bem delineadas, mas que para a expansão do conhecimento não são visíveis. Abarcar os esforços particulares até chegar à dimensão empírica é impossível aqui. Oferecemos, por ora, vários enfoques teóricos com que estamos trabalhando para sustentar o que pode ser considerado um subcampo dos estudos da comunicação: a comunicação intersubjetiva.

\section{UMA DISTINÇÃO BÁSICA: COMUNICAÇÃO INTERPESSOAL E COMUNICAÇÃO INTERSUBJETIVA}

Consideramos que realizar a distinção entre comunicação intersubjetiva e comunicação interpessoal será uma tarefa permanente. Não por que entre ambas não haja pontes comunicantes, ao contrário, justamente porque elas existem e porque, com frequência, os termos passem por sinônimos. Assim, decidimos empreender sua definição sistemática.

Desde seu surgimento, em 2007, o grupo de investigação "Comunicación Intersubjetiva” da AMIC foi marcado pela necessidade de explorar conceitualmente 
${ }^{1}$ No original: "[...] cada relación interpersonal implica alguna forma de comunicación, ya sea intencionada o no. El hombre, en cuanto se encuentra en interacción con otras personas, se está comunicando constantemente. Por su inclinación corpórea no puede dejar de comunicarse, ya que el hombre es todo cuerpo y el encuentro interpersonal se produce en la corporeidade".

${ }^{2}$ No original: "Si tuviéramos que decir con una palabra cuál es el componente central, no el único, el central de la comunicación interpersonal diríamos que es la emoción. Obviamente en la comunicación intersubjetiva el ingrediente dominante es la razón. Ninguna de las dos suele presentarse en estado puro, pues en nuestra comunicación tienden a amalgamarse ambas, emoción y razón. Hay predominio de emoción en la comunicación interpersonal y la capacidad de autocontrol racional es mayoritaria en la intersubjetiva". esse âmbito da comunicação, com frequência relegado a um plano bastante secundário pelo predomínio dos estudos sobre os meios massivos. Como se discutiu na introdução, um dos desafios que vislumbramos com o passar dos anos foi a necessidade de distinguir a comunicação intersubjetiva da comunicação interpessoal, dois termos utilizados muitas vezes como sinônimos e que, apesar de terem o interesse comum por situações de comunicação não mediada, não remetem a situações comunicativas de igual natureza nem podem ser conceitualizados a partir das mesmas matrizes teóricas. Assim, nos últimos anos, o trabalho do grupo, fundamentalmente dos que assinam esse texto, tem se dirigido a explorar essa distinção básica, com o objetivo de conceitualizar com maior rigor o que entendemos por comunicação intersubjetiva. As ideias resultantes desse trabalho, em sua primeira etapa, se consolidam no livro $L a$ comunicación humana en tiempos de lo digital (Fernández; Millán Campuzano; Rizo García, 2013), do qual recuperamos aqui algumas noções básicas.

A comunicação interpessoal é um fato que acontece, não instrumental e que não requer nenhuma teorização (quando queremos pensá-la, já aconteceu). Ao contrário, falar de comunicação intersubjetiva supõe uma aproximação teórica ao fato comunicativo; somente é possível falar dele "na construção racional e consequente de conceitos que já nasceram da teoria” (Millán Campuzano, 2013: 69). Muitas definições da comunicação interpessoal ressaltam sua natureza corpórea:

[...] cada relação interpessoal implica alguma forma de comunicação, intencional ou não. O homem, quando se encontra em interação com outras pessoas, está se comunicando constantemente. Por sua disposição corporal não pode deixar de comunicar-se, pois o homem é todo corpo e o encontro interpessoal se realiza na corporeidade ${ }^{1}$. (Sodhi, 2008: 31)

A comunicação interpessoal, diferente da intersubjetiva, tem um caráter mais senso-corporal e está associada diretamente com a vivência e, em medida bem menor, relaciona-se com a troca de ideias e conceitos ou com a própria informação que está sendo intercambiada:

Se tivéssemos que dizer com uma palavra qual é o componente central, não o único, o central da comunicação interpessoal, diríamos que é a emoção. Obviamente que na comunicação intersubjetiva o componente dominante é a razão. Nenhuma delas geralmente apresenta-se em estado puro, pois nossa comunicação tende a combinar as duas, emoção e razão. Há o predomínio da emoção na comunicação interpessoal e a capacidade de autocontrole racional é majoritária na intersubjetiva². (Fernández, 2013: 34) 


\section{FÁTIMA F, CHRISTLIEB I MARCOA. M. CAMPUZANO | MARTA R. GARCÍA}

São muitos os enfoques e as perspectivas teóricas que podem contribuir para melhor compreender a comunicação intersubjetiva. Nesse trabalho, dividimos os enfoques em sociológicos e filosóficos, pois de acordo com os autores que temos trabalhado no grupo de investigação, estes têm sido os campos de conhecimento que têm produzido mais aportes para conceitualizar a comunicação intersubjetiva.

Em trabalho anterior, propomos, entre outras, as seguintes definições de comunicação intersubjetiva:

[pressupor] um exercício teórico concreto e deliberado de usos da linguagem, na qual os indivíduos capazes de reconhecer-se mutuamente aceitam - em liberdade - construir um espaço comum apropriado à melhor vida possível na coletividade ${ }^{3}$. (Millán Campuzano, 2013: 77)

a comunicação intersubjetiva é a base para a construção dos significados sociais, orientada para o entendimento e para a compreensão e, idealmente, possibilitando os consensos necessários que permitiram, em última instância, um tecido social democrático baseado em argumentos racionais próprios de homens livres que atuam para o bem coletivo4. (Rizo García, 2013: 115)

As definições anteriores destacam a construção de significados orientada ao consenso, o qual requer efetivamente argumentos racionais; porém, em nenhum dos casos se nega ou se anula a presença da emoção, ainda que sem nomeá-la. Afirma Maturana (2004: 108) que "a validade de nossos argumentos racionais não depende de nossas emoções, porém o domínio racional no qual nos encontramos ao conversar, sim"; daí que não seja tão clara a diferença entre a comunicação interpessoal e a comunicação intersubjetiva quanto ao papel que as emoções têm nelas. Para Fátima Fernández (2013: 39-40), a afirmação anterior de Maturana esclarece que "apesar das emoções é possível construir argumentos racionais válidos e, assim, chegar a uma clara comunicação intersubjetiva". Isso obriga a "ter em conta que um esforço de comunicação intersubjetiva pode ser obstacularizado se não considerarmos os componentes emocionais de nossa expressão" (Ibid.: 42).

A comunicação intersubjetiva requer uma interação baseada na consciência, em uma elevada racionalidade argumentativa e na busca do consenso. Apesar do claro domínio do componente racional, não é possível que ocorra numa relação entre sujeitos sem um componente afetivo-emocional; ou pelo menos, se o desejo dos interatores é chegar a consensos, construir discursos coletivos, e num último nível compreenderem-se uns aos outros, sem dúvida a emoção ocupa parte nodal do vínculo estabelecido pelos que estão participando na

\author{
${ }^{3}$ No original: “[...] presupone \\ un ejercicio teórico concreto y \\ deliberado de usos del lenguaje, \\ en el que los individuos capaces \\ de reconocerse mutuamente, \\ han aceptado - en libertad - \\ construir un espacio común \\ apropiado a la mejor vida \\ posible en colectividad". \\ ${ }^{4}$ No original: “[...] la \\ comunicación intersubjetiva \\ es la base para la construcción \\ de los significados sociales, \\ orientada al entendimiento y \\ la comprensión e, idealmente, \\ posibilitadora de los consensos \\ necesarios que permitirían, \\ en último término, un tejido \\ social democrático basado en \\ argumentos racionales propios \\ de hombres libres que actúan \\ por el bien colectivo".
}


interação. Interação que, apesar de conter um grau elevado de formalidade, é talvez pouco espontânea, requer disposições emocionais que contagiem o grupo, fazendo que os sujeitos vejam um objetivo comum em sua interação e se esforcem para construir argumentos racionais relacionados à relação desse desejo compartilhado.

\section{ENFOQUES TEÓRICOS PARA O ESTUDO DA COMUNICAÇÃO INTERSUBJETIVA}

Como se afirmou na introdução, é difícil classificar os autores importantes para o estudo da comunicação intersubjetiva em um espaço disciplinar estanque claro. Porém, com o objetivo único de organizar a exposição, decidimos agrupar os autores com os quais trabalhamos em dois grandes campos: a sociologia e a filosofia. Sem dúvida alguma, ambos os campos de pensamentos são substanciais para compreender a intersubjetividade e sua relação com a comunicação. Em alguns casos é relativamente fácil delimitar em qual dos campos de conhecimento se situa determinado autor. Em outros casos, entretanto, essa classificação não é simples - daí que tenhamos optado por concluir este tópico com a exposição de autores cujos aportes são claramente interdisciplinares.

\section{Enfoques sociológicos}

\section{George Herbert M ead: a personalidade como produto social}

George Herbert Mead é, junto com Erving Goffman, o principal representante do Interacionismo Simbólico, corrente surgida em 1938 que enfatiza a interação dos indivíduos e a interpretação desses processos de comunicação nas situações imediatas, isto é, em um mundo de significados dentro do qual os sujeitos atuam - significados que emanam das permanentes relações de interação social.

O pensamento de Mead ganhou forma na obra Espíritu, persona y sociedad (1968), na qual expressa a prioridade do social sobre o individual. Sua proposta foi "explicar o comportamento do indivíduo em termos da conduta organizada do grupo social, em vez de explicar a conduta organizada do

${ }^{5}$ No original: "explicar la conducta del individuo en términos de la conducta organizada del grupo social en lugar de explicar la conducta organizada del grupo social en términos de la conducta de los distintos individuos que pertenecen a él". grupo social em termos do comportamento dos diferentes indivíduos que pertencem a ele"5 (Mead, 1968: 7). Para o autor, a linguagem tem um papel central na formação da mente e da personalidade, e atua como vínculo entre o individual e o social.

A unidade de análise básica da teoria de Mead é o ato social, um conceito que serviu para dissociá-lo da concepção behaviorista. Mead concebeu os 
estímulos como oportunidades para atuar, e não como compulsões ou ordens que geram respostas automáticas. $\mathrm{O}$ ato social implica duas ou mais pessoas e, nele, os gestos possuem um papel primordial. O autor distinguiu os gestos não significativos dos significativos: os primeiros são aqueles que ocorrem de forma instintiva, irreflexiva e automática, enquanto os significativos são só possíveis no terreno do humano, já que requerem a reflexão por parte do ator antes que se produza a reação. Para Mead, o pensamento é simbólico e a conduta dos seres humanos requer o domínio de símbolos significativos, principalmente da linguagem.

Um dos temas principais de Mead foi elaborar uma teoria da intersubjetividade que concebia a personalidade como um produto social. O principal aporte a esse respeito se encontra no self ou si mesmo, que se refere à capacidade de ver a si mesmo como um objeto, e pressupõe um processo social: a comunicação entre os seres humanos. Quer dizer, o self permite às pessoas participarem em situações de interações com outros e é, portanto, o fundamento da comunicação. Dito de outro modo, quando o indivíduo torna-se consciente de si mesmo e de suas relações com outros similares, possui um self, uma personalidade na medida em que se percebe a si mesmo como unidade de ação. Disse Mead (1968: 184-185) que "somente assumindo o papel de outros somos capazes de voltar a nós mesmos". É a partir da reflexão que o processo social é interiorizado na experiência dos indivíduos implicados nele. A teoria do self, segundo Mead, permitiria a realização de uma espécie de sociedade ideal, baseada na universalidade dos significados, que caracteriza a racionalidade da ciência.

O autor situa o surgimento do self nas duas etapas do desenvolvimento infantil: a etapa do jogo e a do esporte. Durante a primeira, a criança aprende a adotar atitudes de outras crianças reais, enquanto na segunda, a criança já é capaz de adotar o papel de todos os que estão envolvidos na situação de interação. É nessa segunda etapa que as crianças começam a ser capazes de atuar como grupos organizados; nela, Mead incorpora um dos conceitos que mais esclarecem a compreensão do self, o outro generalizado, concebido como a atitude do conjunto da comunidade, que pode ser adotada por um único indivíduo e que permite o desenvolvimento do self deste. Da mesma forma, a adoção da atitude do outro generalizado permite ao sujeito pensar de forma abstrata e objetiva, que o torna capaz de avaliar-se a si mesmo como outros o fariam.

Embora Mead não se refira à comunicação intersubjetiva, sua proposta remete à necessidade da comunicação na construção de significados, que se aprendem na interação com outros. A comunicação simbólica, portanto, permite a conduta inteligente por parte dos sujeitos e a organização social de adaptação ao entorno.
${ }^{6}$ No original: "sólo asumiendo el papel de otros somos capaces de volver a nosotros mismos". 


\section{Alfred Schütz: intersubjetividade e vida cotidiana}

Considerado um dos mais claros representantes da vertente sociológica da fenomenologia, Schütz interessou-se pela interpretação dos significados do mundo e das ações e interações dos sujeitos sociais. Os principais aportes do autor ao pensamento social foram a reinvindicação da sociabilidade como objeto de estudo e a reflexão de que o mundo é conformado por significados socialmente construídos pelas pessoas que vivem nele com uma atitude natural e é intersubjetivo. Cada indivíduo se situa em determinado lugar no mundo, e sua experiência é única e irrepetível. A partir desse lugar, configura-se um repositório de conhecimento disponivel, que armazena as experiências que facilitam a atuação dos sujeitos.

Para Schütz, todas as ações sociais trazem consigo a comunicação, e toda comunicação está baseada em atos para comunicar-se com os outros. Os sujeitos devem realizar atos manifestos no mundo externo que sejam interpretados pelos outros como signos do que se quer transmitir. Por outro lado, a intersubjetividade requer a interação, e em toda situação de interação se produz um contato intersubjetivo. Ambos os conceitos são interdependentes: qualquer interação entre sujeitos pressupõe uma série de construções de sentido comum.

Ainda que Schütz não tenha abordado diretamente a comunicação, de sua proposta emanam alguns juízos básicos sobre ela, a saber: a comunicação precisa de elementos do mundo intersubjetivo da vida cotidiana; a natureza da intersubjetividade é a comunicação entre semelhantes; a possibilidade de compreender os outros depende da existência de relações de mútuo entendimento; para compreender as ações dos outros é necessário não apenas conhecer a materialidade da mensagens, mas também compreender quem as emite; a comunicação é o meio pelo qual os sujeitos superam sua experiência de transcendência dos outros; embora a comunicação seja um elemento básico para a existência da sociedade, não é seu elemento constitutivo; para que exista comunicação, os sujeitos devem compartilhar um mundo e devem compreender esse mundo de uma forma similar a como o outro o compreende; somente são comunicativas as ações que buscam transmitir determinado significado. Tudo isso dá lugar a uma compreensão da comunicação como "compartilhar o fluxo de experiência do outro no tempo interior, este viver através de um presente comum que constitua a experiência de 'nós', que é o fundamento de toda co-

${ }^{7}$ No original: "compartir el flujo de las experiencias del otro en el tiempo interior, este vivir a través de un presente común que constituye la experiencia del 'nosotros', que es el fundamento de toda comunicación posible”. municação possível"' (Schütz, 1974: 173). Portanto, a comunicação permite aos indivíduos sentirem-se "sintonizados" uns com os outros.

A criação do consenso a respeito dos significados da realidade social é resultado das interações de que participam os sujeitos, de modo que o mundo da cotidianidade somente é possível se existe um universo simbólico de sentidos 
compartilhados, construídos socialmente, e que permitem a interação entre subjetividades diferentes. Em conclusão, a subjetividade está inevitavelmente presente em qualquer ato de comunicação, pois este parte das perspectivas dos participantes no ato interativo. Sem interação não há sujeitos sociais, uma vez que a construção de sentidos compartilhados sobre a realidade requer, inevitavelmente, a interação.

Um dos objetos empíricos sobre os quais Schütz refletiu foi a situação social dos imigrantes. Concretamente, em seu texto "O estrangeiro: ensaio de psicologia social”, Schütz estudou “a típica situação em que se encontra um estrangeiro quando procura interpretar o esquema social de um grupo social ao qual se aproxima, e orientar-se dentro dele"8 (Id., 2012: 27). Para os estrangeiros, as pautas culturais aprendidas não funcionam como um sistema disponível de receitas verificáveis e, assim, carecem de um ponto de partida para orientar-se.

\section{Richard Sennett: a habilidade de aprender a escutar}

Esse sociólogo mostra suas referências acadêmicas sem qualquer reticência: "Escrevo no marco de uma longa tradição, a do pragmatismo norte-americano [...] seu caráter distintivo é a investigação de problemas filosóficos inseridos na vida cotidiana"9 (Sennett, 2009: 26). Aponta Charles S. Peirce como o primeiro pragmatista, e em sua lista também aparecem William James e, entre os contemporâneos, Richard Rorty.

Sennett não se propõe em nenhum momento a construir uma teoria da comunicação humana, porém, seu desejo de analisar os obstáculos que no dia a dia impedem o respeito, a cooperação e a emergência de novas formas de organização social o levam a fazer aportes fundamentais para a comunicação intersubjetiva.

Ao estudar as desigualdades entre os seres humanos, esse autor distingue os dons naturais, cuja variedade é ampla, das diferenças causadas pela organização social, distanciando-se da desigualdade vivida como divisão entre fortes e fracos, uma vez que isso desempenha um papel perturbador tanto em uns quanto em outros. Ele defende um tipo de igualdade baseada na autonomia: "Mais do que uma igualdade de compreensão, a autonomia significa aceitar nos outros o que não podemos compreender deles"10 (Id., 2003: 264). Há níveis de comunicação que não é possível alcançar com ímpetos de vontade, em razão de desigualdades naturais profundas. No terreno da outra, da desigualdade construída socialmente, aí sim há terreno fértil para o entendimento.

Sennett tampouco se propõe a incursionar na chamada comunicação social, nem quer analisar sociologicamente os meios, entretanto, ao estudar a conexão entre trabalho e cidadania observa que "as notícias do jornalismo cor-de-rosa
${ }^{8}$ No original: "la situación típica en que se encuentra un forastero cuando procura interpretar el esquema cultural de un grupo social al que se acerca, y orientarse dentro de él".

${ }^{9}$ No original: "Escribo en el marco de una larga tradición, la del pragmatismo norteamericano $[\ldots]$ su carácter distintivo es la búsqueda de problemas filosóficos insertos en la vida cotidiana".

${ }^{10}$ No original: "Más que una igualdad de comprensión, la autonomía significa aceptar en los otros lo que no podemos comprender de ellos". 


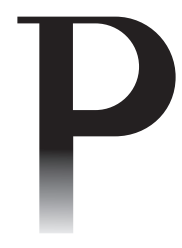

${ }^{11}$ No original: "las noticias del periodismo rosa $\mathrm{y}$ sensacionalista o los blogs llenos de trivialidades personales no contribuyen a desarrollar un tipo más elaborado de comunicación".

${ }^{12}$ No original: "transmitir respeto es encontrar las palabras y los gestos que permitan al otro no sólo sentirlo, sino sentirlo con convicción".

${ }^{13}$ No original: "Saber escuchar requiere otro conjunto de habilidades, las de prestar cuidadosa atención a lo que dicen los demás e interpretarlo antes de responder, apreciando el sentido de los gestos y los silencios tanto como el de los enunciados".

e sensacionalista ou dos blogs cheios de trivialidades pessoais não contribuem para desenvolver um tipo mais elaborado de comunicação"11 (Id., 2009: 357). A isso complementa que as instituições e ferramentas de comunicação da democracia moderna não se inspiram no desenvolvimento das competências que a maioria das pessoas utiliza no trabalho.

Em seu trabalho sociológico sobre a dignidade do ser humano em um mundo de desigualdade, o autor conclui que o respeito é um comportamento expressivo, ou seja, que tratar os demais com respeito não é algo que acontece simplesmente sem mais, nem sequer com a melhor vontade do mundo, pois "transmitir respeito é encontrar as palavras e os gestos que permitem ao outro não apenas senti-lo, mas senti-lo com convicção"12 (Id., 2003: 213).

Em seus trabalhos mais recentes, não apenas sublinha esse tipo de aportes sobre a comunicação humana em suas dimensões mais profundas, mas faz emergir explicitamente suas convicções sobre o que é necessário para alcançar um ato comunicativo inequívoco. Disse Sennett que quando falamos de habilidade de comunicação, normalmente nos concentramos na maneira de realizar uma exposição clara e buscamos apresentar o que pensamos e sentimos - questão que requer habilidades, que, nesse caso, são de natureza declarativa. "Saber escutar requer outro conjunto de habilidades, as de prestar cuidadosa atenção ao que dizem os outros e interpretar antes de responder, apreciando o sentido dos gestos e dos silêncios, tanto quanto o dos enunciados"13 (Id., 2012: 30).

Sua forma de trabalho intercala elementos teóricos na narrativa sobre realidades sociais precisas e localizáveis.

\section{Randall Collins: emoções e rituais de interação}

A proposta das cadeias de rituais de interação de Randall Collins traz elementos para pensar a dimensão emocional dos processos de comunicação. Para o autor, a maioria dos aspectos de nossas vidas se movem impulsionados por uma força comum, os rituais de interação, que não apenas criam e recriam símbolos de pertencimento grupal, mas também infundem energia emocional em seus participantes. Todos fluímos de uma situação a outra atraídos pelas interações que nos oferecem maior benefício emocional.

Os rituais de interação são situações de copresença física que separam os participantes de outros e que variam conforme o grau de coincidência desses participantes em seu foco de atenção compartilhado e conforme a intensidade da ligação emocional que surja entre eles. Quando nas interações se alcança um nível elevado de coincidência no foco da atenção e na emoção compartilhados, os participantes podem experimentar solidariedade grupal, sentimento de pertencimento, confiança, força e iniciativa para a ação. 
O que aumenta ou diminui a energia emocional é a consonância de gestos comunicativos e ritmos emocionais entre os participantes de determinado ritual de interação. Essa consonância é "inerente à intersubjetividade humana"14 (Collins, 2009: 148). A energia emocional se acumula em lembranças, ideias, crenças e símbolos e se recicla em redes de conversação, em diálogos interiores e em cadeias de rituais de interação que ocorrem posteriormente. Quanto maior for a identificação pessoal com os símbolos do grupo, maior será a sobrevivência individual da memória simbólica e do sentimento de pertencer a esse grupo.

Collins não distingui em nenhum momento a comunicação interpessoal da comunicação intersubjetiva; entretanto, por meio do conceito de energia emocional, o autor indica que toda dinâmica de interação está cheia desse tipo de energia. Para ele, toda situação de comunicação parte de um encontro de corpos plenos de emoções e, também, de consciência do efeito de encontros vividos e experimentados anteriormente. Sua concepção dos rituais de interação tem no consenso um componente importante. Aqui já parece haver uma aproximação à comunicação intersubjetiva: quando existe um foco de atenção compartilhado, gera-se um grau maior de consenso, e isso faz que os participantes tenham um sentimento de pertencimento ao grupo - sentimento que faz nascer a energia emocional, e que, por sua vez, produz nos indivíduos sentimentos como a confiança em si mesmos, o entusiasmo e o desejo de que os atos executados pelo grupo continuem sendo moralmente corretos. A comunicação intersubjetiva requer uma interação baseada na consciência, na elevada racionalidade argumentativa e na busca do consenso. Apesar do claro domínio do componente racional, não é possível que ocorra um contato entre sujeitos sem um componente afetivo-emocional; ou, ao menos, se o desejo dos interatores é chegar a consensos, construir discursos coletivos e, em última instância, compreenderem-se uns aos outros, sem dúvida a emoção toma parte nodal do vínculo que estabelecem os participantes de determinado ritual de interação - um ritual que, embora possa conter elevado grau de formalidade e ser pouco espontâneo, diria Collins, requer disposições emocionais que contagiem o grupo, que façam que os sujeitos vejam um objetivo comum em sua interação e se esforcem para construir argumentos racionais que encaminhem a realização desse anseio compartilhado.

\section{Enfoques filosóficos}

\section{Martin Heidegger: ser-com-outros}

Ver o nome desse pensador relacionado à intersubjetividade pode gerar dúvidas iniciais no leitor, pois, como se sabe, parte decisiva de sua obra visa a
${ }^{14}$ No original: “inherente a la intersubjetividad humana”. 
${ }^{15}$ No original: "La maquinación exige, en toda clase de desenmascaramientos de las variadas violencias, la calculabilidad preabarcable por completo del poder sujetante del ente para la organización disponible; de esta exigencia esencial, pero a la vez oculta, procede la técnica moderna". desconstruir a noção de sujeito moderno, o que, numa variação mais extensiva, é possível fazer com o conceito de intersubjetividade; entretanto, acreditamos que nisso se encontra sua originalidade e força de provocação para a compreensão do fenômeno comunicativo intersubjetivo. Em especial, a ideia de ser-com-outros, como intrínseca e propriamente humana, é possível colocá-la em relação com a de intersubjetividade. Considerar o ser-com-outros nos levaria a territórios poucos explorados em nosso campo de estudos e, no enfoque de nossa investigação, serviria para manter um alerta ontológico, em que seja necessário suscitá-lo. À maneira de exemplo é que mencionamos o que se segue.

A crítica da versão mais recente da metafísica ocidental que o segundo Heidegger realizou, entendendo-a como maquinação, remete à preocupação com o domínio do pensamento calculador da ciência e da tecnologia contemporâneas. A cibernética propriamente dita exerce essa função maquínica que se infiltrou em toda a organização da vida como gestell. "A maquinação exige, em todo tipo de desmascaramentos das variadas violências, a calculabilidade preabarcável por inteiro do poder sujeitante do ente para a organização disponível; dessa exigência essencial, porém por vezes oculta, decorre a técnica moderna"15 (Heidegger, 2006: 30). Os processos de informação e comunicação teletecnológica e científica contemporâneos são, sob essa luz, os mais claros transmissores do pensar-calculador da metafísica de nossa época e ocorrem nas mais variadas formas da vida cotidiana.

As considerações anteriores pertencem ao chamado segundo Heidegger, depois de Ser e Tempo. Tanto sua obra-chave quanto sua elaboração prévia dão indicações sobre o enfoque que Heidegger irá expor sobre o modo do estar-no-mundo: para o ser humano corresponde fazê-lo a partir da ocupação e do cuidado (sorge), a partir do coestar enquanto solicitude e do estar em si mesmo como alguém. O ser humano (Dasein) permanece em estado de abertura, aberto ao mundo, a si mesmo, ao ser e aos demais, de um modo constitutivo do que ele é. Nessas formas constitutivas situam-se tanto a disposição afetiva quanto a compreensão, e essas, por sua vez, são determinadas pelo discurso (rede). No sentido da disposição afetiva é que se diz que o Dasein está, desde sempre, animicamente adaptado em seu estar-com-outros, frente ao ente e ante si mesmo.

O discurso, compreendido como o articulado (logos) na interpretação de um modo existencialmente originário no compreender, junto da disposição afetiva, conforma o sentido em um todo de significações. O discurso se exterioriza como linguagem e se des-articula como palavra-coisa e dá lugar ao convívio-compressor. O discurso é relatado e abre as possibilidades de articulação em significações de compreensão afetivas de uns-com-outros e assim poder escutar-nos (uns aos outros): 
O escutar a alguém é o existencial estar aberto ao outro, próprio do Dasein enquanto coestar. O escutar constitui inclusive a primária e autêntica abertura do Dasein a seu poder-ser mais próprio, como um escutar da voz do amigo que todo Dasein porta consigo. [...] O escutar-se uns aos outros, em que se configura o coestar, pode assumir a forma de um "dar atenção" ao outro, de estar de acordo com ele, e aos modos privativos de não querer-escutar, de opor-se, de obstinar-se e dar as $\operatorname{costas}^{16}$. (Heidegger, 2003: 186)

Embora, como é notório, na obra de Heidegger não seja cabível a expressão metafísica da intersubjetividade, é justamente em formulações como ser-no-mundo e sua correspondente ser-com-outros que se compreende o modo que sustenta a abertura comunicativa do ente humano e se entende como ontologicamente constitutiva de seu modo de ser mais próprio (e não "mais essencial"). Por outro lado, consideramos que esse autor, difícil e polêmico como é, aporta novo vigor para pensar a própria comunicação a partir de outro início e a partir de seus aportes sistemáticos - tanto pelo modo como estabelece o ser humano em seu ser mais específico como a partir de sua crítica às condições metafísicas de nossa sociedade da informação conformada pela cibernética (de qualquer ordem que seja) -, trazendo, assim, benefícios integradores a novos modos de compreender o humano ou o demasiado humano.

\section{Jürgen Habermas: o sentido racional da comunicação intersubjetiva}

A obra de Habermas tem sido uma constante nas reflexões que, como grupo, temos desenvolvido em torno da comunicação intersubjetiva. E embora tenhamos refletido sobre suas ideias, com maior cuidado, em outros escritos nossos, aqui desejamos oferecer algumas ideias que resumam o tratamento teórico a que ele tem sido submetido em nossos estudos.

Ainda que a vasta obra de Habermas tenha passado por enfoques disciplinares distintos, que vão da sociologia à ciência política, passando por questões relativas à justiça ou à vida boa, é no núcleo central de sua teoria da ação comunicativa que se encontram seus aportes mais substanciais e originais, vale dizer: a formulação de uma teoria da argumentação, uma teoria social e do espaço público que, a partir do enfoque da virada linguística, torna possível a formulação do reconhecimento intersubjetivo por meio de pretensões de validade universais.

Para Habermas, a filosofia renunciou há muito a suas tarefas de vigilância de disputas metafísicas para assumir o papel de intérprete entre a cultura especializada (política, científica, legislativa etc.) e o grande público que se vê afetado por ela. A racionalidade argumentativa, ou racionalidade comunicativa, colocará em cena direta ou de representação (quando houver um terceiro incluído) uma intersubjetividade que se sustenta na obtenção de consensos para

\section{${ }^{16}$ No original: "El escuchar a alguien es el existencial estar abierto al otro, propio del Dasein en cuanto co-estar. El escuchar constituye incluso la primaria y auténtica apertura del Dasein a su poder-ser más propio, como un escuchar de la voz del amigo que todo Dasein porta consigo [...] El escucharse unos a otros, en el que se configura el coestar, puede cobrar las forma de un 'hacerle caso' al otro, de un estar de acuerdo en él, y los modos privativos del no querer-escuchar, del oponerse, del obstinarse y dar la espalda".}


${ }^{17}$ No original: "meta del entendimiento es la producción de un acuerdo, que termine en la comunidad intersubjetiva de la comprensión mutua, del saber compartido, de la confianza recíproca y de la conducta de unos con otros".

${ }^{18}$ No original: "el sentimiento de dependencia y el sentido de la relevancia del trato con los otros".

${ }^{19}$ No original: "hacia aquellas posiciones filosóficas que acentúan la constitución intersubjetiva del espíritu humano". o reconhecimento da inserção das pretensões de validade por meio dos atos de fala, os quais os participantes, em uma distribuição simétrica de oportunidades, escolhem e executam livremente.

Assim, propõe-se que toda disputa a respeito de algum tema ou problema que afeta determinada comunidade terá que buscar atingir um acordo racionalmente motivado, a partir do uso das pretensões de validade: "objetivo do entendimento é a produção de um acordo, que resulte na comunidade intersubjetiva da compreensão mútua, do saber compartilhado, da confiança recíproca e da conduta de uns para com os outros"17 (Habermas, 1993: 301). Isto é, que todo aquele que atue comunicativamente (argumentativamente) deve ser inteligível ("compreensão mútua”), emitir um conteúdo proposicional suscetível de aceitação racional ("saber compartilhado"), expressar intenções sinceras ("confiança recíproca") e concordar com um pano de fundo normativo ("conduta de uns para com os outros").

Devedora de uma concepção pragmática da linguagem, a teoria da ação comunicativa fixou suas posições em uma ética do discurso, a partir de KarlOtto Apel, na construção da validade intersubjetiva dos acordos racionalmente motivados, porém não é alheia à experiência vital do próprio Habermas, que encontra um nexo entre teoria e biografia, pois, como ele mesmo conta, uma "nasalização deficiente" em razão de diversas intervenções cirúrgicas devido a lábio leporino despertarem nele, desde cedo, "o sentimento de dependência e o senso de relevância do trato com os outros"18 (Id., 2006: 21), dando sentido ao enunciado de que toda obsessão (teórica) tem raízes biográficas, uma vez que, ademais, isso o motivou a dirigir-se "até aquelas posições filosóficas que ressaltam a constituição intersubjetiva do espírito humano"19 (loc. cit.).

As raízes biográficas, nesse caso, são algo mais do que simples anedotas para a construção de uma teoria, pois nos mostram que, de fato, toda a teoria racional, de ação ou especulativa, se fundamenta no solo firme de um mundo concreto da vida, no qual as emoções desempenham um papel de motivação de uma teoria da construção da validade intersubjetiva (construção de consenso). As dificuldades de expressão comunicativa do próprio Habermas - e as consequentes dificuldades em seus círculos de convivências - embora não sejam fatores diretos na construção da teoria da ação comunicativa representaram um elemento importante para a elaboração de uma teoria não excludente da comunicação humana. $O$ fator de simetria e não exclusão em uma comunidade que debate o melhor para si mesma é, sem dúvida, uma peça-chave no pensamento de Habermas.

Por outro lado, os escritos recentes do próprio Habermas (cf. Habermas, 2016) têm mostrado o avanço crescente da teoria da ação comunicativa - e 
da ética do discurso que a subjaz - na construção de processos democráticos cooperativos quando, na esfera do público, se torna necessário reconhecer a participação simétrica dos atingidos pelo estado de direito e o fluxo de expressões comunicativas no mundo atual, pois essa teoria aborda a capacidade de construir acordos que legitimem as decisões às quais os cidadãos cheguem legalmente, em uma construção democrática. A construção democrática pode ainda suprir bastante e com proveito a teoria da ação comunicativa, pois constitui uma via de vigilância argumentativa para legitimar acordos por meio do consenso argumentativo. A constituição do reconhecimento intersubjetivo é uma necessidade da consolidação de processos democráticos de envergadura diversa e por isso a proposta de Habermas nos parece bastante frutífera.

$\mathrm{Na}$ medida em que podemos ser testemunhas de uma comunicação que, com plenitude, afirme as relações intersubjetivas, a teoria da ação comunicativa continua sendo uma fonte de fundamentação não transcendental para atingir o fortalecimento dos vínculos humanos em prol de uma racionalidade que promova acordos racionais no reconhecimento de uns com os outros.

Somos conscientes de que Habermas merece um maior espaço, porém nosso objetivo está delimitado em oferecer enfoques no marco das dimensões desse artigo.

\section{Michel Onfray: rumo a um cinismo lúdico-intersubjetivo}

$\mathrm{Na}$ obra de Michel Onfray é possível compreender alguns vínculos que unem a intersubjetividade com a liberdade. Inspirado por uma erudição que resgata pensadores não canonizados pelas instituições de ensino, da antiguidade ao tempo presente, e por ações humanas reais, vivas, mais do que por meros discursos metafísicos e idealistas, a perspectiva do filósofo francês defende uma proposta ética de construção de si - uma escultura de si - a partir do reconhecimento de uma intersubjetividade libertária e lúdica.

Em toda relação humana há um grau zero, no qual surge a situação e no qual a presença do desejo do outro faz que, num primeiro nível, advenham perguntas-chave no sentido existencial concreto: "O que quer de mim?"; "O que diz?”; “O que deseja?”; “Como apresenta seu projeto de vida?". E, então, ocorre ou não a troca de informação, seja para atingir outros níveis de relação ou tomar boa distância dela, evitando o desprazer. Na vida cotidiana, mesmo não cientes de tudo, colocamos em jogo nossas habilidades éticas nos vínculos humanos-afetivos que vamos criando. É claro que a coisa é um tanto mais problemática.

E é porque derivamos de uma história sociocultural ocidentalizada que desembocamos em relações humanas complexas e bastante sinistras, cujos 
${ }^{20}$ No original: "la sumisión drástica del animal en cada uno y el nacimiento de lo humano en el hombre".

\footnotetext{
${ }^{21}$ No original: "considera a la ética como una modalidad del estilo y proyecta la esencia de éste en una existencia que se vuelve lúdica".
}

sintomas, que acreditamos "normais", se resumem no fato de não sabermos viver em liberdade. Onfray elabora uma lista não exaustiva desses sintomas: nosso gosto pelo frívolo e efêmero, nossa preferência pela subordinação ao poder - aqui, ao contrário, Onfray costuma referir-se ao famoso encontro entre Alexandre Magno e o filósofo-cão Diógenes -, as honras de mérito, a mesquinharia em suas variadas ilustrações, o conformismo retrogrado e a estreiteza dos projetos, entre outros, que além disso funcionam como forma de decepções a priori, nas quais se perdem as possibilidade de autossuficiência, de autonomia e de governo de si mesmo. Daí sua formulação de uma intersubjetividade hedonista, na qual, ademais, a ética se faz desejável e defende-se a "submissão drástica do animal em cada um e o nascimento do humano no homem"20 (Onfray, 2008: 107).

De teor decididamente anti-idealista e com traços de um cinismo crítico (ou quinismo, se se prefere), a intersubjetividade proposta por Onfray (2009: 33) recupera o corpo, os fluídos, o sangue, a bondade, uma erótica solar (em oposição a uma obscura e cavernosa), uma vontade estética que "considera a ética como uma modalidade de estilo e projeta a essência deste em uma existência que se torna lúdica" ${ }^{21}$. A vida cotidiana é o lugar da formação da escultura de si que tecemos nas relações intersubjetivas livres, ágeis, elegantes e delicadas, contra as pesadas, escuras, tradicionais (judaico-cristã-muçulmanas) e estreitas.

Essa intersubjetividade, para ser decididamente libertária, propõe atingir relações de uns com os outros nas quais se antecipe a arte, o atlético e o terapêutico, pois é na nossa vida real e cotidiana que se encontram nossos possíveis dons de ser para o outro, e para si, um corpo que se harmoniza em sua própria autoconstrução, que resolve atleticamente em ocasiões oportunas os desafios da vida com um toque lúdico e onde somos alento e medicina mútua a partir de uma coordenação amorosa, embora não idealizada. Onfray, finalmente, se pronuncia pela busca da sabedoria, mas não da santidade.

\section{Enfoques interdisciplinares}

\section{Norbert Elias: representações simbólicas}

A formação multidisciplinar desse autor (medicina, filosofia, sociologia) o leva a trabalhar com uma mirada interdisciplinar que combina visões compatíveis da realidade e que não distinguem fronteiras entre os conhecimentos gerados em algum território delimitado do saber.

O último dos trabalhos escritos por ele, Teoría del símbolo (Elias, 1994), tem como fio condutor a comunicação que geramos por meio das representações simbólicas características da espécie humana. Nessa obra incompleta, o autor indaga as etapas evolutivas pelas quais passaram os antepassados da humanidade 
em seu trajeto, desde os sinais majoritariamente inatos, por meio de cantos ou grunhidos, até a comunicação mediante linguagens articuladas. Interroga igualmente a biogênese do uso de padrões sonoros socialmente regulamentados como símbolos do próprio objeto da comunicação.

O marco geral de sua obra é o esboço de uma teoria da evolução humana, por isso, ao estudar o universo simbólico socialmente criado, se pergunta pela linguagem humana e indica a diferença com respeito às espécies animais precedentes. Os humanos diferem de outros seres vivos pelo fato de seus principais meios de comunicação, que são os padrões sonoros - não característicos de toda a espécie, mas da sociedade em que eles foram criados. Esses padrões sonoros que chamamos "idiomas" não são fixados geneticamente, mas obra humana, e o membro individual de uma sociedade os adquire por meio de um longo processo de aprendizagem. O potencial para nos comunicarmos é, ao mesmo tempo, herança biológica e aprendizado social.

Nos comunicamos, diz Elias, por meio de uma ampla gama de padrões sonoros, alguns inatos, como o choro de um recém-nascido e a maioria aprendidos na sociedade em que vivemos. A comunicação por meio de símbolos aprendidos é - enfatiza o autor - uma peculiaridade da espécie humana, a única capaz de formular perguntas, e com isso ter um ponto de partida para construir novo conhecimento. Não é possível esquecer, acrescenta também, "que as linguagens não apenas tornam possível a comunicação, mas que também a limitam"22 (Elias, 1994: 57). A linguagem chega até a raiz das formas de pensar aprendidas e algumas sociedades não encontram palavras para o que vivem coletivamente.

Outro tema desenvolvido ao longo de sua obra é a possibilidade de articular as distintas visões disciplinares sobre os fenômenos humanos por meio de um marco integrador que permita a comunicação entre visões completares. Os exemplos mais eloquentes que o autor apresenta remetem à comunicação entre a psiquiatria e a sociologia, assim como entre esta e a biologia.

Nas palavras dele, a teoria do símbolo constitui uma ajuda para "unificar teorias que são consideradas normalmente áreas separadas e inclusive independentes da existência humana como a linguagem, conhecimento e pensamento"23 (Ibid.: 129).

Seu método de trabalho é a construção de modelos ou figurações sociais extrapoláveis a realidades semelhantes para compreendê-las e explicá-las.

Humberto Maturana: a linguagem como domínio da coordenação consensual

Maturana é um doutor em Biologia por Harvard. Jamais planejou elaborar uma teoria da comunicação, porém seus estudos sobre a organização dos seres vivos desembocaram não apenas numa forte crítica às teorias da comunicação que se ensinavam nos anos 1970, mas também em propostas teóricas que nos
${ }^{22}$ No original: "que los

lenguajes no sólo hacen posible la comunicación sino que también la limitan". 
${ }^{24}$ No original: "El origen del lenguaje, como un dominio de coordinaciones conductuales consensuales, exige una historia de encuentros recurrentes en la aceptación mutua suficientemente intensos y prolongados".

No original: "En la vida cotidiana nos movemos de un dominio racional a otro en el curso de nuestro emocionar, muchas veces sin darnos cuenta. Por esto, el fluir de los discursos racionales en las interacciones humanas depende del fluir emocional de las conversaciones en que éstas se dan. Esto a menudo no lo vemos porque corrientemente somos ciegos a nuestro emocionar. En suma, la validez de nuestros argumentos racionales no depende de nuestras emociones, pero el dominio racional en que nos encontramos en cada instante al conversar, si". obrigam a olhar a linguagem e as conversações a partir de nossa constituição biológica e social.

Maturana, sendo biólogo, afirma que a linguagem como processo não tem lugar no sistema nervoso, mas sim no espaço de coordenações de conduta consensuais que se elabora no fluir dos encontros com os outros. Desde $E l$ árbol del conocimiento (1996), escrito em 1984 com Francisco Varela, até seus recentes escritos para o Instituto Matríztica por ele fundado, fazem referência precisa ao processo de comunicação.

Maturana, assim como Norbert Elias, se pergunta pela origem da linguagem e a explica a partir do fenótipo ontogênico, mesmo não estando determinado geneticamente, mas a partir das ontogenias possíveis com que nasce um organismo, o meio em que se desenvolve atua como causador de mudanças. Houve um momento, explica o biólogo, há três milhões e meio de anos, em que o tipo de convivência das comunidades humanas ofereceu tudo o que era necessário para que a linguagem surgisse; foi o modo de vida hominídeo que a tornou possível. Sintetizado nas palavras do autor: "A origem da linguagem, como um domínio coordenações de conduta consensuais, exige uma história de encontros recorrentes na acepção mútua, suficientemente intensos e prolongados" ${ }^{24}$ (Maturana, 2004: 104).

Em relação à diferença entre comunicação interpessoal e comunicação intersubjetiva, Maturana oferece pistas claras:

Na vida cotidiana nos movemos de um domínio racional a outro no curso de nosso emocional, muitas vezes sem percebermos. Por isso, o fluir dos discursos racionais nas interações humanas depende do fluir emocional das conversações em que estas ocorrem. Não vemos isso com frequência, porque geralmente somos cegos ao nosso emocional. Em suma, a validade de nossos argumentos racionais não depende de nossas emoções, porém o domínio racional em que nos encontramos a cada momento ao conversar, $\operatorname{sim}^{25}$. (Ibid.: 108)

Se não percebo como uma emoção se infiltra em meu argumento, estou num ato de comunicação interpessoal, mas se consigo ser consciente de minhas emoções ao emitir um argumento racional, me encontro diante de um ato de comunicação intersubjetiva.

O método de Maturana, desde que concebeu a ideia de autopoiese (a mesma que depois Luhmann usaria), tem sido postular perguntas de investigação derivadas da original: "De onde provém a organização do indivíduo e qual é o mecanismo que a determina?". A fenomenologia biológica tem procurado sempre a plena validação no domínio observacional. 


\section{CONCLUSÃO E PERSPECTIVA}

A comunicação intersubjetiva não pode ser abordada a partir de um único ponto de vista. Não é possível nem seria saudável para o progresso do conhecimento com respeito a ela e a fenômenos afins que despertam o nosso interesse como grupo de investigação. Assim, ensaiamos aqui um esquema conceitual que integra, se não todos, muitos dos autores e perspectivas que nos têm servido para colocar sobre a mesa ideias e juízos básicos sobre o tema. $\mathrm{O}$ desafio é que essas ideias de autores tão distintos - e distantes em suas ideias - possam convergir em formas empíricas de abordar as situações de comunicação intersubjetiva. Naturalmente, estamos conscientes que vários autores, temas e debates ficaram de fora, pois é impossível querer abarcar tantas discussões no marco de um artigo que se limita a oferecer alguns resultados preliminares.

Esse parece ser o processo natural do grupo de investigação "Comunicación Intersubjetiva" da AMIC: de um lado, será importante discutir a dimensão metodológica da comunicação intersubjetiva - Como investigá-la? Em que âmbitos da vida cotidiana? Com que instrumentos técnicos? Que tipos de dados serão obtidos? Como intervir na comunicação intersubjetiva a partir dos dados empíricos gerados previamente? -; por outro lado, muitos dos componentes teóricos continuarão seu curso em termos de permanecer indagando e debatendo aportes e pormenores das teorias e autores já revisados para adquirir profundidade e capacidade de discussão. Essas e outras indagações serão parte de nossas discussões posteriores. Até aqui, portanto, nos interessou apenas organizar e comunicar um mapa de autores, conceitos e ideias que, consideramos, servem como base para a abordagem teórica da comunicação intersubjetiva. E consideramos haver colocado suficiente ênfase nas diferenças e afinidades que vinculam a comunicação interpessoal e a comunicação intersubjetiva, tendo como consequência novas perguntas e novas necessidades de expansão na construção epistemológica de um âmbito de investigação chave para a comunicação contemporânea. M

\section{REFERENCIAS}

COLLINS, R. Cadenas de rituales de interacción. Barcelona: Anthropos, 2009. FERNÁNDEZ CHRISTLIEB, F. El trasfondo emocional de la comunicación interpersonal (y el difícil tránsito hacia la comunicación intersubjetiva. In: FERNÁNDEZ CHRISTLIEB, F.; MILLÁN CAMPUZANO, M.; RIZO GARCÍA, M. (Coords.). La comunicación humana en tiempos de lo digital. Cidade do México, DF: Universidad Autónoma Metropolitana Cuajimalpa; Juan Pablos, 2013. p. 29-68. 
FERNÁNDEZ CHRISTLIEB, F; MILLÁN CAMPUZANO, M.; RIZO GARCÍA, M. (Coords.). La comunicación humana en tiempos de lo digital. Cidade do México, DF: Universidad Autónoma Metropolitana Cuajimalpa; Juan Pablos, 2013.

FERNÁNDEZ CHRISTLIEB, F.; RIZO GARCÍA, M. (Coords.). Nosotros y los otros: la comunicacion humana como fundamento de la vida social. Cidade do México, DF: Los Miércoles, 2009.

ELIAS, N. Teoría del símbolo. Barcelona: Península, 1994.

HABERMAS, J. En la espiral de la tecnocracia. Madri: Trotta, 2016.

. Entre naturalismo y religión. Barcelona: Paidós, 2006.

. Teoría de la acción comunicativa: complementos y estudios previos.

Cidade do México, DF: REI, 1993.

HEIDEGGER, M. Meditación. Buenos Aires: Biblos, 2006.

. Ser y tiempo. Madri: Trotta, 2003.

MATURANA, H. Desde la biología a la psicología. Buenos Aires: Universitaria; Lumen, 2004.

MATURANA, H.; VARELA, F. El árbol del conocimiento. Madri: Debate, 1996.

MEAD, G. H. (1934). Espiritu, persona y sociedad: desde el punto de vista del conductismo social. Madri: Paidós, 1968.

MILLÁN CAMPUZANO, M. Reflexiones desde el umbral: comunicación interpersonal y comunicación intersubjetiva. In: FERNÁNDEZ CHRISTLIEB, F.; MILLÁN CAMPUZANO, M.; RIZO GARCÍA, M. (Coords.). La comunicación humana en tiempos de lo digital. Cidade do México, DF: Universidad Autónoma Metropolitana Cuajimalpa; Juan Pablos, 2013. p. 69-89.

ONFRAY, M. Cinismos, retrato de los filósofos llamados perros. Buenos Aires: Paidós, 2009. . La fuerza de existir. Barcelona: Anagrama, 2008.

RIZO GARCÍA, M. De lo interpersonal a lo intersubjetivo: algunas claves teóricas y conceptuales para definir la comunicación intersubjetiva. In: FERNÁNDEZ CHRISTLIEB, F.; MILLÁN CAMPUZANO, M.; RIZO GARCÍA, M. (Coords.). La comunicación humana en tiempos de lo digital. Cidade do México, DF: Universidad Autónoma Metropolitana Cuajimalpa; Juan Pablos, 2013. p. 91-123.

SCHÜTZ, A. El forasteiro: ensayo de psicología social. In: SIMMEL, G. et al. El extranjero: sociología del extraño. Madri: Sequitur, 2012. p. 27-42.

. Estudios sobre teoría social. Buenos Aires: Amorrortu, 1974.

SENNETT, R. El artesano. Barcelona: Anagrama, 2009.

.El respeto: sobre la dignidad del hombre en un mundo de desigualdad. Barcelona: Anagrama, 2003. 
. Juntos: rituales, placeres y política de cooperación. Barcelona: Anagrama, 2012.

SODHI, J. Incomunicabilidad de la persona y comunicación interpersonal. 2008.

78 f. Tese (Licenciatura em Psicología) - Universitat Abat Oliva CEU, 2008.

Disponível em: <https://goo.gl/q6mB5r >. Acesso em: 4 jan. 2014.

VILLORO, L. Creer, saber, conocer. México DF: Siglo XXI, 1982.

Artigo recebido em $1^{\circ}$ de março de 2016 e aprovado em 2 de março de 2017. 